\title{
COMPARAÇÃO ENTRE OS TEORES DE CARBOIDRATOS TOTAIS SOLÚVEIS PRESENTES EM DISTINTAS FRAÇÕES DA LEVEDURA Saccharomyces cerevisiae MEYEN
}

\author{
MENDES-COSTA, M.C. ${ }^{1}$ e MORAES, W. B. C. ${ }^{2}$ \\ ${ }^{1}$ Departamento de Biologia, Universidade Federal de Lavras, C.P. 37, CEP 37200-000, Lavras, MG, Brasil \\ ${ }^{2}$ Seção de Bioquímica Fitopatológica, Instituto Biológico, C.P. 7119, CEP 01064-970, São Paulo, SP, Brasil \\ Correspondência para: Maria Cristina Mendes Costa, Rua Tiradentes, 540, CEP 78200-000, Cáceres, MT, Brasil \\ Recebido em 02/03/98 - Aceito em 29/06/98 - Distribuído em 23/02/99
}

(Com 6 figuras)

\section{ABSTRACT \\ Comparison between the content of all soluble carbohydrates present in distinct fractions of the yeast Saccharomyces cerevisiae}

Strains of Saccharomyces cerevisiae were quantitatively compared to the content of all soluble carbohydrates present in two kinds of fraction: the "washed" and the lysate fraction with the purpose of identifying the richest fraction to be used in programs of induction of disease protection in plants. The sugar contents in the "washed" fraction were related to residues from the culture medium and not to extracellular components. Preliminary assays determined criotrituration as an adequate method of cellular lysis. Relevant observation has been made regarding to the variability of all sorts of carbohydrate content present in the lysate fraction of different strains.

Key words: carbohydrates, cell wall, elicitors, phytoalexin.

\section{RESUMO}

Linhagens de Saccharomyces cerevisiae foram quantitativamente comparadas quanto ao teor de carboidratos totais solúveis presentes em dois tipos de fração: o "lavado" e o "lisado", com o objetivo de identificar a fração mais rica para ser utilizada em programas de indução de proteção em plantas. Os teores de açúcares encontrados na fração "lavado" foram relacionados com os resíduos do meio de cultura e não com os componentes extracelulares. Testes preliminares determinaram a criotrituração como método adequado de lise celular. Observação relevante foi a grande variabilidade do teor de carboidratos presente no lisado de diferentes linhagens.

Palavras-chave: carboidratos, parede celular, elicitores, fitoalexina.

\section{INTRODUÇÃO}

A parede celular da levedura Saccharomyces cerevisiae Meyen é um complexo contendo polissacarídeos, pouca quantidade de quitina, fosfato e proteínas (Manners et al., 1973). O nome genérico "glucanas" cobre um grande grupo de polímeros de D-glucose que se diferenciam tanto no tipo quanto nas proporções relativas das ligações glicosídicas individuais (Farkas, 1979). As glucanas isoladas de S. cerevisiae, assim como as de Phytophtora megasperma Drechs. f. sp. glycinea
(Hildb) Kuan \& Erwin, mostraram-se ativas em tecidos de várias plantas, como a soja (Hahn \& Albersheim, 1978), feijão e batata (Cline et al., 1978) e outras, estimulando a produção de fitoalexinas. Silva (1989) demonstrou que a antracnose do milho pode ser controlada em experimentos de casa de vegetação pela inoculação prévia das folhas com uma suspensão ou filtrado de células de $S$. cerevisiae. Os componentes extracelulares detectados em filtrado de cultura de fitopatógenos também foram capazes de estimular a formação de fitoalexinas em tecidos de 
seus hospedeiros (Tepper \& Anderson, 1986; Coleman et al., 1992). Guzzo \& Moraes (1997) demonstraram a existência de substâncias extracelulares em urediniosporos de Hemileia vastatrix Berkeley et Broome, capazes de desencadear a formação de fitoalexina em cotilédones de soja. Os carboidratos isolados das paredes do extrato comercial de $S$. cerevisiae e de linhagens de laboratório possuem comportamento semelhante ao do patógeno $P$. megasperma, atuando como elicitores da fitoalexina gliceolina, quando são colocados em contato com os tecidos da soja (Guzzo \& Moraes 1997; Mendes-Costa \& Moraes, 1998a). Os híbridos entre linhagens da levedura mostraram possuir diferentes teores de carboidratos totais solúveis. O teor de carboidratos totais solúveis mostrou ser determinado por fatores genéticos quantitativos (Mendes-Costa \& Moraes, 1998b), podendo ser utilizado como marcador para a seleção de linhagens de $S$. cerevisiae destinadas à indução de fitoalexinas.

As leveduras têm sido intimamente associadas com o progresso do bem-estar da raça humana. Os estudos genéticos e bioquímicos têm sido feitos utilizando-se $S$. cerevisiae, por ser um organismo de fácil manejo em laboratório, tendo a vantagem de não ser patogênico. Aliando-se a tantas atribuições positivas que este microrganismo possa ter, a presente pesquisa teve como principal objetivo comparar quantitativamente polissacarídeos extraídos de duas frações ou extratos de diferentes linhagens, buscando identificar aquelas mais ricas em carboidratos, e que possam ser utilizadas no possível aproveitamento deste microrganismo em programas de indução de proteção em plantas.

\section{MATERIAL E MÉTODOS}

O material utilizado no presente trabalho constituiu-se de três linhagens de $S$. cerevisiae, sendo uma linhagem comercial de fermento biológico Fleischmann e duas outras linhagens de laboratório, ATCC 26698 e GRF-18. As linhagens de levedura foram submetidas a dois tipos de tratamento, com a finalidade de se verificar a variabilidade existente em relação à quantidade de polissacarídeos totais solúveis: lavagem superficial das células que constituiu a fração denominada "lavado" e lise celular que constituiu a fração denominada "lisado". Em frascos de Erlenmeyer de $100 \mathrm{ml}$, contendo $50 \mathrm{ml}$ de meio YEPD líquido,
( $1 \%$ de extrato de levedura, $2 \%$ de peptona, $2 \%$ de glicose e $2 \%$ de ágar) foi inoculada uma linhagem controle da levedura (ATCC 26698). Estes frascos foram deixados sob agitação durante vinte e quatro horas a $30{ }^{\circ} \mathrm{C}$ com iluminação natural, e após centrifugação $(3.000 \mathrm{~g})$ por dez minutos para retirada do meio de cultura, as células foram lavadas com água destilada por duas vezes consecutivas e o volume completado para $50 \mathrm{ml}$.

Uma alíquota de $1,5 \mathrm{ml}$ foi, então, retirada e, a partir daí, as células foram deixadas em agitação, em câmara fria $\left(6^{\circ} \mathrm{C} \pm 2\right)$. Em intervalos de tempo determinados, $0,0,5,2,6,10,24$ e 48 horas, foram sendo retiradas alíquotas para posterior análise da presença de açúcar. As alíquotas retiradas foram submetidas a um teste colorimétrico de antrona (Dishe, 1962) e o teor de açúcar quantificado.

A fração extracelular derivada da lavagem das células foi submetida a uma série de testes a fim de esclarecer 1) se a quantidade de açúcares presente no "lavado" era resíduo do meio de cultura ou se era devido a polissacarídeos excretados pelas células; 2) se a quantidade de açúcar colocada no meio de cultura era total ou parcialmente consumida; 3) qual o percentual de oscilação existente no conteúdo de açúcar em várias repetições; 4) qual a percentagem mínima de carboidratos necessária para o crescimento normal da levedura. Os testes foram feitos utilizando-se a linhagem ATCC-26698 e uma linhagem duplo-mutante GRF18 para aminoácidos com três repetições. As linhagens foram crescidas em meio líquido de YEPD a $30^{\circ} \mathrm{C}$, sob agitação. Após o crescimento por vinte e quatro horas, retirou-se o meio de cultura por centrifugação e, utilizando-se o teste colorimétrico de antrona, quantificou-se o teor de açúcar do meio.

O mesmo foi feito com a fração derivada da primeira e da segunda lavagem das células ("lavado"). Para verificar a percentagem ideal de carboidratos para o crescimento da levedura, variações do teor de glicose do meio de cultura foram feitas. Com o objetivo de estabelecer um método de lise celular que pudesse ser utilizado com eficiência, foram empregados inicialmente três procedimentos diferentes, cujos resultados foram comparados ao microscópio: 1) trituração com desintegrador celular tipo Hannover (bastão de vidro esmerilhado); 2) ultra-som (Sonorex; mod. RK 103) com potência de 50-60 HZ; e 3) criotrituração. 


\section{RESULTADOS}

1) Variação do teor de glicose no meio de cultura

A Fig. 1 mostra o peso fresco das linhagens ATCC-26698 de S. cerevisiae crescidas em decrescentes concentrações de glicose. Nota-se que a concentração inicial de glicose do meio é um fator limitante do crescimento, principalmente para a linhagem mutante. A linhagem controle (ATCC26698) teve o seu crescimento reduzido, mas mesmo assim conseguiu crescer quando a concentração de glicose inicial do meio foi de $0,0 \%$.

2) Variação do teor de carboidratos totais solúveis no meio de cultura para crescimento das linhagens ATCC-26698 e GRF-18 de S. cerevisiae

$\mathrm{O}$ teor inicial de carboidratos, tanto do meio de cultura livre de células quanto do "lavado", foi quantificado nas respectivas variações da concentração de glicose, como pode ser visto na Fig. 2. No "lavado" pode-se constatar que a presença de açúcares está relacionada com a concentração inicial do meio de cultura.

Esta observação pode ser comprovada pelos dados da Fig. 2 que mostram a dosagem ao se fazer apenas uma lavagem das células. Ao proceder à segunda lavagem, o teor de carboidratos teve uma queda acentuada, o que pode ser confirmado pelos dados da Fig. 6.

3) Variação do teor de carboidratos totais solúveis da fração "lavado" da linhagem ATCC-26698 de S. cerevisiae, após diferentes intervalos de tempo Os dados anteriores são corroborados pelos resultados dos testes feitos com a fração "lavado" da linhagem ATCC-26698 de S. cerevisiae, para determinar se a fração extracelular derivada da lavagem das células apresentava ou não enriquecimento posterior de polissacarídeos ao meio de cultura. Observa-se que, independentemente do tempo deixado em agitação, o teor de carboidratos totais solúveis não apresentou nenhum aumento significativo. Ao contrário, diminuiu consideravelmente do intervalo de tempo zero a quarenta e oito horas. Tais constatações determinaram que a fração "lavado" não proporciona o enriquecimento do meio com açúcares extracelulares além daqueles pertencentes ao meio de cultura original. A quantidade de carboidratos da fração "lavado" não cresceu proporcionalmente ao tempo de agitação, isto é, o teor de açúcares do tempo zero e após quarenta e oito horas não teve um aumento significativo, como mostrado pelo teste " $\mathrm{t}$ " em nível de 5\% (Fig. 3).

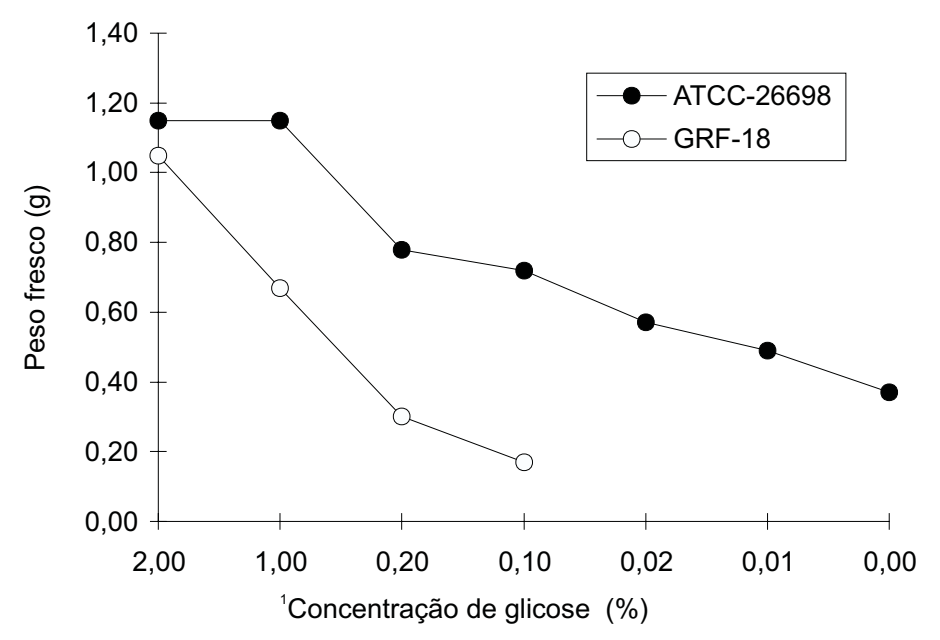

Fig. 1 - Peso fresco das linhagens ATCC-26698 e GRF-18 de S. cerevisiae crescidas em diferentes concentrações de glicose. 1. Concentração de glicose do meio de crescimento (YEPD) tomada em porcentagem do total. 


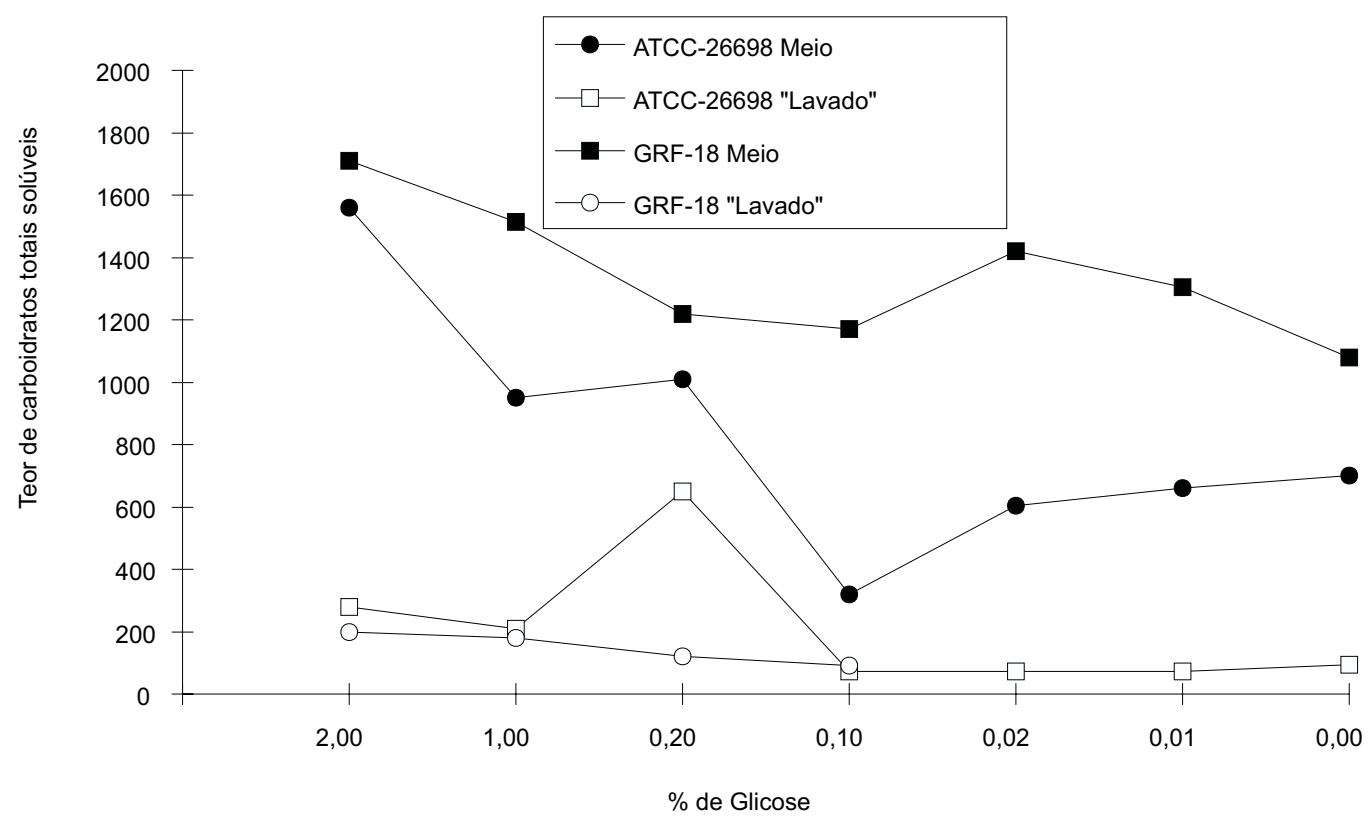

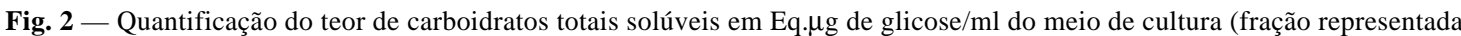
pelo meio de cultura livre de células onde se desenvolveram as linhagens de S. cerevisiae) e do "lavado" (fração representada pela lavagem das células de $S$. cerevisiae separadas do meio de cultura), após crescimento, das linhagens ATCC-26698 e GRF-18 de S. cerevisiae, em presença de diferentes concentrações de glicose no meio de cultura.

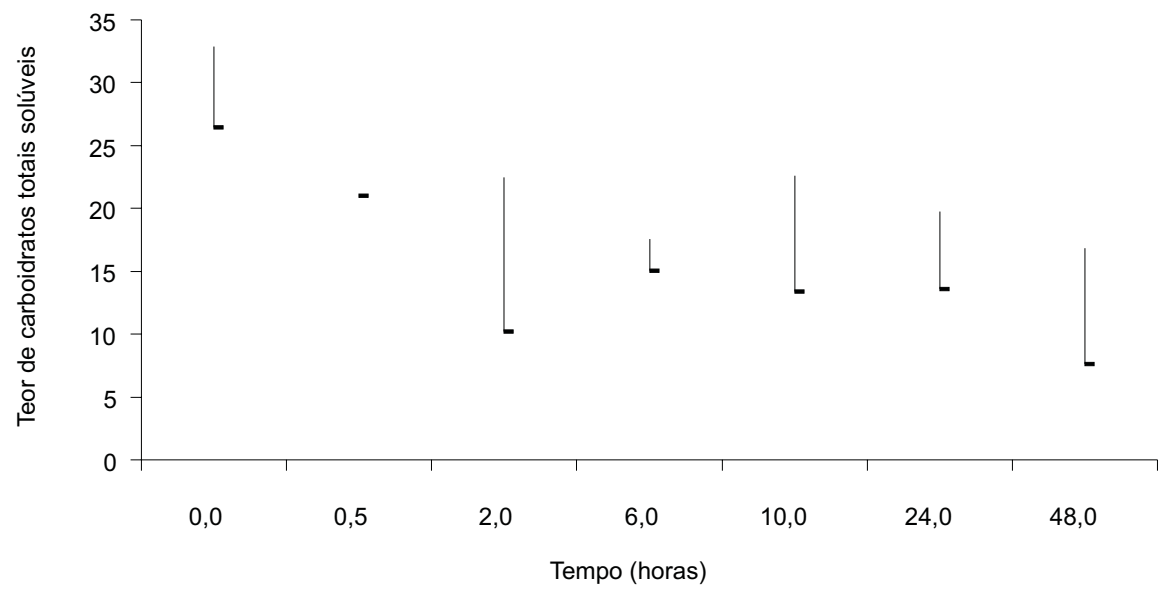

Fig. 3 - Variação do teor de carboidratos totais solúveis em Eq. $\mu$ g de glicose/ml da fração "lavado" da linhagem ATCC-26698 de culturas de $S$. cerevisiae, crescidas em diferentes intervalos de tempos a partir do tempo zero (as frações obtidas nos tempos 2, 6, 10, 24 e 48 horas são significativamente diferentes da média do tempo zero em nível de $5 \%(\mathrm{P}<0,05)$ (teste-Tukey). 


\section{4) Definição do método de lise celular}

Observações ao microscópio óptico constataram a presença de $100 \%$ de células completamente intactas, resultantes da tentativa de lise, tanto pelo desintegrador celular Hannover quanto pelo ultra-som. A desintegração mecânica, em presença de nitrogênio líquido acrescido de carborundum, foi o único procedimento que apresentou ao microscópio células completamente lisadas. Por conseguinte, demonstrou ser o método mais eficiente, apesar de mais trabalhoso e demorado.

\section{5) Comparação da oscilação do teor de carboidratos em várias repetições}

O teor de carboidratos totais solúveis da fração "lavado" não foi aumentando significativamente com o tempo de agitação (Fig. 3). O método de lise celular selecionado foi submetido a repetições com o objetivo de constatar a sua confiabilidade, uma vez que o método em si, por depender da força mecânica do experimentador, poderia resultar em dados não reproduzíveis. A Fig. 4 mostra o peso em gramas das repetições feitas com as linhagens ATCC-26698, GRF-18 e uma linhagem comercial de fermento biológico Fleischmann (FL). Pode-se observar que o crescimento da linhagem comercial FL não chegou a 1,0 g. A diferença entre as médias foi significativa em nível de 5\% pelo teste Tukey. Observa-se, também, que o crescimento foi regular nas quatro (4) repetições.

Em relação ao crescimento, constatou-se variação na velocidade de crescimento entre as três linhagens, sendo que a linhagem comercial cresceu menos em comparação com as outras, nas mesmas condições de laboratório. Pela análise de variância e teste de Tukey, houve diferença significativa também entre as linhagens ATCC-26698 e GRF-18. O coeficiente de variação foi 4,32 .

A Fig. 5 mostra os resultados da taxa de polissacarídeos do "lisado" e a Fig. 6 refere-se ao "lavado". Quatro repetições foram feitas com três linhagens diferentes: a linhagem ATCC-26698, a GRF-18 e uma linhagem comercial de fermento biológico Fleischmann (FL). Verifica-se que houve uma variação estatisticamente significativa no teor de carboidratos da fração "lisada" (Fig. 5) entre as linhagens, demonstrada pelo teste de Tukey. A linhagem ATCC-26698 apresentou um teor de carboidratos superior aos das outras duas linhagens. O coeficiente de variação encontrado foi 18,2.

Quanto ao "lavado" (Fig. 6), a linhagem GRF-18 apresentou uma diferença estatisticamente significativa em relação à linhagem FL, como pode ser constatado pelo teste de Tukey. O coeficiente de variação encontrado foi 25,335 .

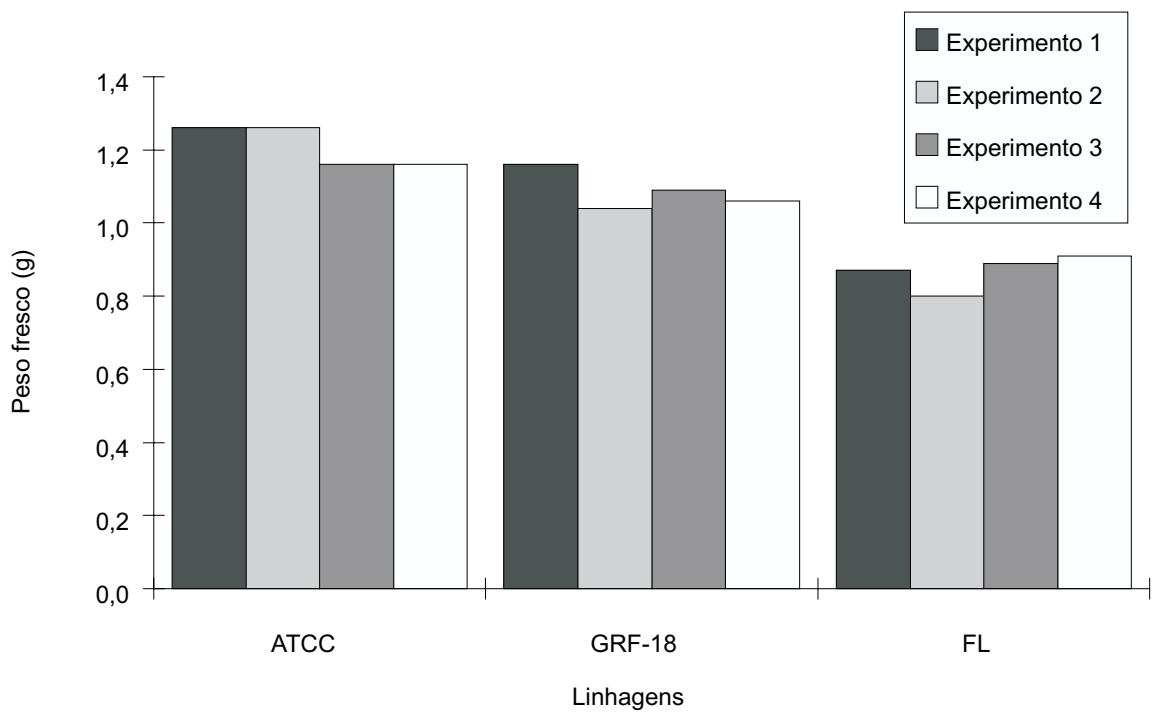

Fig. 4 - Peso fresco em gramas das linhagens ATCC-26698, GRF-18 e FL de S. cerevisiae, crescidas em meio completo líquido (YEPD), antes de lise celular. Médias das linhagens ATCC $=1,21 * \pm 0,06$; GRF-18 $=1,09 * \pm 0,05$ e FL $=0,89 \pm$ 0,02. Médias seguidas de asterisco são significativamente diferentes da linhagem FL em nível de $5 \%(P<0,05)$ (teste-Tukey). 


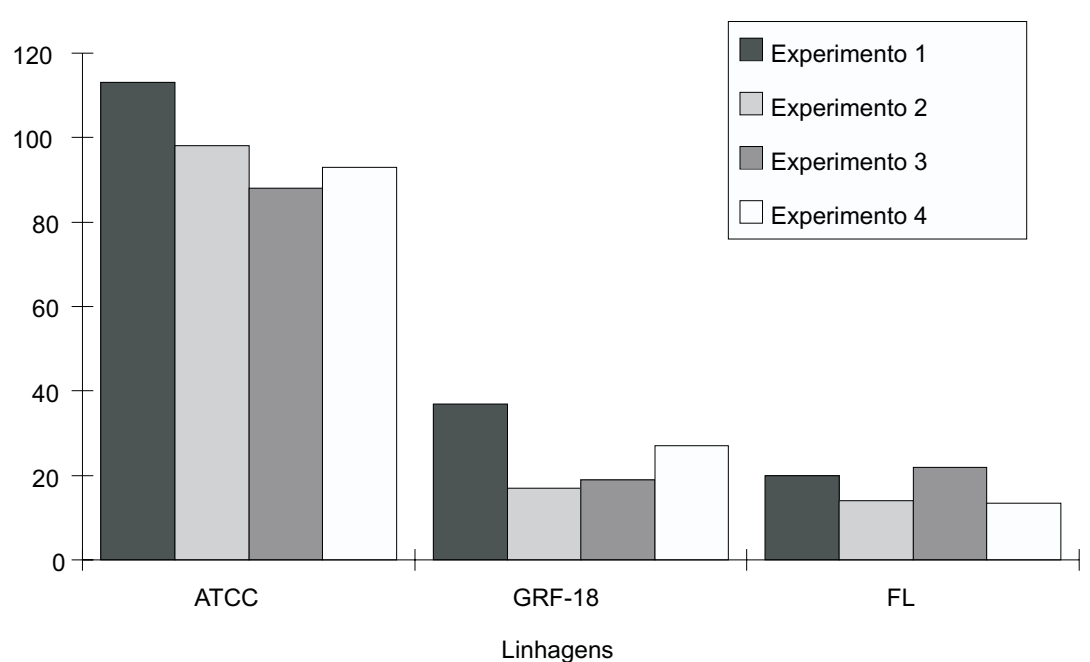

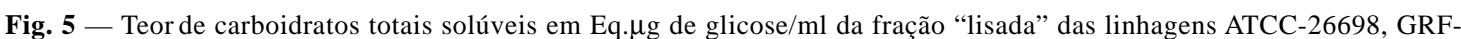
18 e FL de culturas de $S$. cerevisiae, crescidas em meio completo líquido (YEPD), em quatro repetições. Médias das linhagens ATCC-26698 $=98^{*} \pm 10,80$; GRF-18 $=25 \pm 9,09$ e FL $=17,38 \pm 4,27$. Médias seguidas de asterisco são significativamente diferentes da linhagem FL em nível de $5 \%(\mathrm{P}<0,05)$ (teste-Tukey).

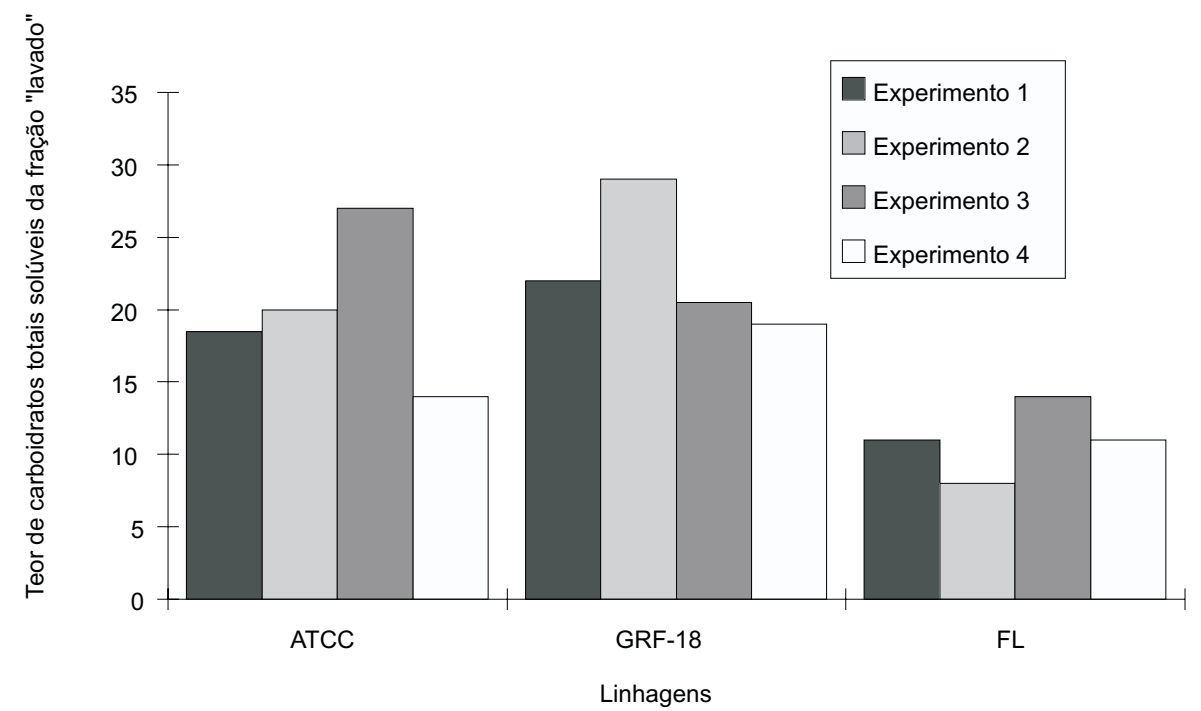

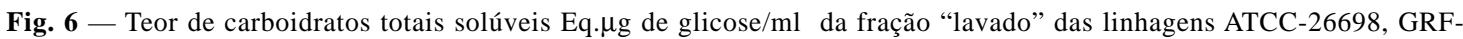
18 e FL de culturas de $S$. cerevisiae, crescidas em meio completo líquido, em quatro repetições. Médias das linhagens ATCC$26698=19,88 \pm 5,39 ; \mathrm{GRF}-18=22,63^{*} \pm 4,42$ e $\mathrm{FL}=11,0 \pm 2,45$. Médias seguidas de asterisco são significativamente diferentes da linhagem FL em nível de $5 \%(\mathrm{P}<0,05)$ (teste-Tukey).

\section{DISCUSSÃO}

Os testes feitos com a fração "lavado," visando o conhecimento do comportamento de diferentes linhagens nas condições desejadas, foram executados com as linhagens que são nutricionalmente diferentes: ATCC-26698 e mutante GRF-18.
A análise dos dados da Fig. 1 mostra que a concentração de glicose mínima necessária para o crescimento da linhagem GRF-18 foi de $2 \%$ e, assim sendo, esta taxa foi mantida nos testes seguintes. Com a redução da concentração de glicose para 1\%, a linhagem ATCC-26698 manteve o crescimento, decaindo lentamente nas dosagens 
subseqüentes e mantendo-se mesmo em meio desfavorável.

Em relação à concentração de glicose no meio de cultura, Polakis \& Bartley (1966) citam $0,9 \%$, enquanto $2 \%$ é a concentração usada por pesquisadores da área, fazendo parte da composição básica do meio para crescimento de levedura (Fink, 1970). Os resultados aqui apresentados comprovam ambos os dados da literatura, uma vez que, diferenças consideráveis foram observadas na taxa de crescimento das linhagens e devem ser levadas em consideração. O crescimento da linhagem ATCC26698 foi praticamente o mesmo com a concentração $2 \%$ e $1 \%$ de glicose na composição do meio de cultura, valor bem próximo ao de Polakis \& Bartley (1966), enquanto para a linhagem mutante, o mínimo necessário foi 2\% (Fig. 1). A linhagem mutante não se desenvolveu sem glicose no meio e a ATCC-26698 teve um desempenho maior do que a GRF-18, quando esta cresceu em um meio com $0,2 \%$ de glicose.

Possivelmente, isto deveu-se à utilização pela ATCC-26698 de açúcares liberados por outros componentes do meio de cultura. A linhagem mutante, não sendo capaz de utilizar estes resíduos, teve seu crescimento paralisado.

Segundo Barnett (1976), cada linhagem de levedura tem uma taxa de crescimento própria que se modifica se qualquer uma das condições ambientais for mudada (temperatura, requerimentos nutricionais etc.). Concluiu-se, pois, que a concentração de glicose deve ser ajustada de acordo com as necessidades de cada linhagem.

Os testes com a fração "lavado" visaram, também, a obtenção de informações sobre a variação do teor de carboidratos totais solúveis no meio de cultura. Comparando-se o teor de carboidratos totais solúveis encontrado no meio de cultura, após crescimento da linhagem-controle, com o encontrado no meio da linhagem mutante, nota-se que no primeiro caso a quantidade de açúcares decresceu concomitantemente à concentração de glicose do meio. Isto não ocorreu no segundo caso, sugerindo a utilização dos açúcares liberados pelos outros componentes do meio de cultura, após sua degradação, pela linhagem ATCC-26698 e não pela GRF-18.

O teor de carboidratos totais solúveis presente no meio de cultura da linhagem mutante GRF-18 permaneceu, praticamente, inalterado nas diferentes variações de glicose testadas. O teor de carboidratos da linhagem-controle ATCC-26698 foi reduzido, aproximadamente, pela metade. Os resultados mostrados na Fig. 2 são consistentes com a pressuposição anterior, de que a linhagem ATCC-26698 utilizou açúcares liberados por outros componentes do meio.

Comparando-se os dados do teor de carboidratos presente no meio de cultura com o presente no "lavado", nota-se que este decresceu concomitantemente à concentração de açúcar do meio. As evidências sugerem que o açúcar presente na fração "lavado" é resíduo do meio de cultura e não proveniente do metabolismo celular da levedura. Tal afirmação ficou fortalecida quando se verificou a variação do teor de carboidratos totais da fração "lavado" em diferentes intervalos de tempo. A diferença, estatisticamente significativa, entre o teor de carboidratos presente no "lavado" no primeiro intervalo de tempo (Fig. 3), em relação aos seguintes, sugere que a levedura $S$. cerevisiae não produz polissacarídeos extracelulares em quantidades detectáveis pelo método utilizado para a fração "lavado".

Quanto ao "lisado", vários métodos de lise celular são descritos. Nickerson (1963) cita quebra mecânica por colisão ou impacto, quebra por ultrasom (20-30 HZ) e exposição à ação enzimática. Em qualquer dos casos, o material celular deve ser separado do meio para as análises subseqüentes. $\mathrm{O}$ autor salienta que as células da levedura $S$. cerevisiae são muito resistentes para serem quebradas por ultra-som. O tempo gasto para a quebra da levedura é muitas vezes maior do que para células de bactérias ou de outros gêneros de levedura. Os dados aqui obtidos estão de acordo com a observação citada, pois mesmo usando-se um aparelho de ultra-som com potência superior ao citado pelo referido autor, as células da levedura não se romperam.

Entretanto, Abd-El-Al \& Phaff (1968) conseguiram resultados com eficiência entre $50 \%$ e $95 \%$ utilizando um aparelho de ultra-som $(20 \mathrm{kc} /$ seg.), mas não mencionaram o tempo. A quebra mecânica por agitação com cristais de vidro em desintegrador do tipo "Mickle" foi usada por Northcote \& Horne (1952); McMurrough \& Rose (1967); e Power \& Challinor (1969), durante uma hora, para quebrar células normais da levedura. Outros autores utilizaram a quebra mecânica com um homogeneizador tipo "Braun"(Fleet \& Manners, 1976). 
O princípio da quebra mecânica, com modificações, foi utilizado neste trabalho por meio de: 1) quebra mecânica por trituração executada pelo experimentador; 2) acréscimo de carborundum (limalhas de ferro) às células; 3 ) trituração em presença de nitrogênio líquido. $O$ congelamento imediato das células juntamente com o carborundum, somados à força física exercida pelo experimentador, contribuíram para a lise celular. Uma das desvantagens em relação aos demais métodos mencionados relaciona-se com a participação direta do pesquisador no processo, aumentando o erro experimental. Esta desvantagem, porém, é compensada quando se verifica que este método pode ser introduzido em laboratórios desprovidos de aparelhagem mais sofisticada, sendo que o tempo gasto para trituração mecânica é também de uma hora. A análise dos dados apresentados nas Figs. 5 e 6 permite-nos salientar que: 1) os dados referentes às repetições são reproduzíveis; 2) existe oscilação do teor de açúcar entre as repetições, maior no "lisado"; 3) há variabilidade quanto ao teor de carboidratos encontrado em cada linhagem; 4) este fenômeno é uma característica própria de cada linhagem; 5) a linhagem comercial FL mostrou-se estatisticamente inferior às outras no teor de carboidratos, tanto do "lavado" como do "lisado". As repetições executadas com três linhagens (Fig. 5) mostram que os desvios são aceitáveis, apesar da existência de oscilação no teor de açúcar entre as mesmas, e a identidade de cada linhagem não foi prejudicada.

Acrescenta-se a isto uma percentagem de erro inerente a qualquer teste químico de quantificação, o fato de se ter como padrão a média de três repetições para cada amostra e, ainda, o controle do tempo. A variação existente entre os teores de açúcares do lisado entre as linhagens poderia ser atribuída ao peso diferenciado das mesmas. Pela Fig. 4 verifica-se que o peso das linhagens ATCC26698, GRF-18 e FL são estatisticamente diferentes e apresentaram diferenças significativas no teor de açúcares presente no "lisado" (Fig. 5). Por esta razão, o desempenho igual na taxa de crescimento foi rigorosamente controlado a fim de não interferir na quantificação de açúcares, tanto do "lisado" quanto do "lavado".

A quantidade de células submetida à trituração certamente influi no resultado. A diferença, estatisticamente significativa, encontrada entre as linhagens ATCC-26698, GRF-18 e FL pode ser devida também ao crescimento diferenciado das mesmas, apesar da variação ter ocorrido mesmo entre repetições com o mesmo peso.

Agradecimentos - À Coordenação de Aperfeiçoamento de Pessoal de Nível Superior (CAPES), à Dra. Elizabeth Vicente (USP) por ter cedido a linhagem GRF-18 e ao Dr. Ronaldo Bastos Francini pela ajuda na elaboração dos gráficos.

\section{REFERÊNCIAS BIBLIOGRÁFICAS}

ABD-EL-AL, A. T. H. \& PHAFF, H. J., 1968, Exo- $\beta$-glucanases in yeast. Biochem. J., 109: 347-360.

BARNETT, J. A., 1976, The utilization of sugars by yeasts. Advanc. Carbohyd. Chem. Biochem., 32: 125-234.

CLINE, K., WADE, M. \& ALBERSHEIM, P., 1978, Hostpathogen interaction. XV. Fungal glucans which elicit phytoalexin accumulation in soybean also elicit the accumulation of phytoalexin in other plants. Plant. Physiol., 62: 918-921.

COLEMAN, M. J., MAINZER, J. \& DICKERSON, A. G. 1992, Characterization of a fungal glycoprotein that elicits a defense response in French bean. Physiol. Mol. Plant Pathol., 40: 333-351.

DISHE, Z., 1962, General color reaction. In: R.L. Whistler \& M.L. Wolfrom (eds.), Methods in Carbohidrate Chemistry, Academic Press., 1: 478-512.

FARKAS, V., 1979, Biosynthesis of cell walls of fungi. Microbiol. Rev., 117-144.

FINK, G. R., 1970, The biochemical genetics of yeast. Methods Enzimol., 17: 59-78.

FLEET, G. H. \& MANNERS. D. J., 1976, Isolation and composition of an alkali-soluble glucan from the cell walls of Saccharomyces cerevisiae. J. Gen. Microbiol., 94: 180-192.

GUZZO, S. D. \& MORAES, W. B. C., 1997, Purificação e caracterização parcial de um elicitor de fitoalexina em soja, a partir de urediniosporos de Hemileia vastatrix. Fitopatol. Bras., 22(3): 396-402.

HAHN, M. G. \& ALBERSHEIM, P., 1978, Host-pathogen interactions. XIV. Isolation and parcial characterization of an elicitor from yeast extract. Plant Physiol., 62(1): 107-111.

MANNERS, D. J., MASSON, A . J., PATTERSON, J. C. BJORNDAL, H. \& LINDBERG, B., 1973, The structure of a $\beta$-(1-6)-D-glucan from yeast cell walls. Biochem. J., 135: 31-36.

MCMURROUGH, I. \& ROSE, A. H., 1967, Effect of growth rate and substrate limitation on the composition and structure of the cell wall of Saccharomyces cerevisiae. Biochem. J., 105: 189-203.

MENDES-COSTA, M. C. \& MORAES, W. B. C., 1998a, Acúmulo da fitoalexina gliceolina em cotilédones de soja por frações lisadas da levedura Saccharomyces cerevisiae. Ciênc. e Agrotec., no prelo. 
MENDES-COSTA, M. C. \& MORAES, W. B. C., 1998b, Selection of strains of Saccharomyces cerevisiae Meyen by quantification of total soluble carbohydrates present in the cellular lysate. Rev. Microbiol., 29(2): 122-126. no prelo.

NICKERSON, W. J., 1963, Symposium on biochemical bases of morphogenesis in fungi. IV. Molecular bases of form in yeasts. Bacteriol. Rev., 27: 305-324.

NORTHCOTE, D. H. \& HORNE, R. W., 1952, The chemical composition and structure of the yeast cell wall. Biochem. J., 51: 232-236.

POLAKIS, E. S. \& BARTLEY, W., 1966, Changes in dry weight, protein, desoxyribonucleic acid, ribonucleid acid and reverse and estructural carbohydrate during the aerobic growth cycle of yeast. Biochem. J., 68: 883-887.
POWER, D. M. \& CHALLINOR, S. W., 1969, The effects os inositol-deficiency on the chemical composition of the yeast cell wall. J. Gen. Microbiol., 55: 169-176.

SILVA, S. R. da, 1989, Aspectos do controle da antracnose em plantas de milho (Zea mays L.) mantidas em casa de vegetação pelo emprego de Saccharomyces cerevisiae Meyen. Dissertação de Mestrado, ESALQ/USP, Piracicaba, SP, 81p.

TEPPER, C. S. \& ANDERSON, A. J., 1986, Two cultivars of bean display a differential response to extracellular components from Colletotrichum lindemuthianum. Physiol. Mol. Plant Pathol., 29: 411-420. 